LETTER TO JMG

\title{
Identification of a novel mutation disrupting the DNA binding activity of GCM2 in autosomal recessive familial isolated hypoparathyroidism
}

\author{
L Baumber, C Tufarelli, S Patel, P King, C A Johnson, E R Maher, R C Trembath
}

J Med Genet 2005;42:443-448. doi: 10.1136/jimg.2004.026898

$\mathrm{H}$ ypoparathyroidism is a heterogeneous group of disorders with both acquired and inherited causes, each presenting clinically with hypocalcaemia. Familial cases of hypoparathyroidism may be due to an isolated defect of the parathyroid glands or be a component of a syndrome disorder, examples of which include DiGeorge, hypoparathyroidism-retardation-dysmorphism, and KennyCaffey syndrome. ${ }^{1}$ Familial isolated hypoparathyroidism (FIH) is characterised by hypocalcaemia and hyperphosphataemia and may be due to an inherited deficiency or the abnormal activity of parathyroid hormone (PTH). FIH is heterogeneous with $\mathrm{X}$ linked, autosomal dominant, and autosomal recessive modes of inheritance reported. ${ }^{2}$ Mutations in the PTH gene on chromosome llp have been described in both autosomal dominant and autosomal recessive forms of the disorder. ${ }^{3}$ Mature PTH is generated by cleavage of the signal peptide from the prepro-PTH, followed by successive proteolysis of pro-PTH within the Golgi apparatus. ${ }^{5}$ A requirement for normal PTH processing is emphasised by the detection of FIH disease causing mutations, which include two missense amino acid substitutions within the signal region of the prepro-PTH gene, leading to inefficient cleavage by signal peptidases. ${ }^{3}$

Heterozygous defects in the calcium sensing receptor (CASR) have been detected in autosomal dominant FIH and sporadic cases of hypoparathyroidism. ${ }^{6-8}$ All known CASR mutations in FIH lead to receptor activation. ${ }^{9}{ }^{10}$ The CASR normally functions to provide a negative feedback loop, whereby binding of extracellular $\mathrm{Ca}^{2+}$ activates the receptor, resulting in decreased PTH secretion by parathyroid cells, but also through inhibition of calcium reabsorption in the renal distal tubule. Constitutive activation of this receptor therefore results in hypocalcaemia and hypercalciuria.

Notwithstanding these reports, the molecular genetic basis of most cases of autosomal recessive FIH remains unknown. Recently, a homozygous deletion within the human GCM2 (glial cells missing, Drosophila homologue B, previously referred to as $G C M B$ ) gene has been shown to underlie hypoparathyroidism in one patient from a kindred with no consanguinity. ${ }^{11}$ GCM2 belongs to a family of novel transcription factors characterised by an N-terminal DNA binding domain, known as the gcm motif. ${ }^{12}{ }^{13}$ This motif, unique to the GCM family, spans approximately 150 amino acids, exhibiting approximately $92 \%$ identity between human and mouse homologues. ${ }^{14}$ Human GCM1 and GCM2, the two identified isoforms of GCM, display additional homology to their mouse counterparts outside this region with GCM2 showing $68 \%$ and $47 \%$ similarity overall to Gcm 2 and GCM1, respectively. ${ }^{15}$ Despite limited characterisation of human GCM, studies on the expression pattern of mouse $\mathrm{Gcm} 2$ protein have shown it to be confined to the developing parathyroid gland ${ }^{16}$ and homozygous mutant mice lacking the Gcm 2 gene demonstrate absence of parathyroid tissue and

\section{Key points}

- Hypoparathyroidism is a heterogeneous group of disorders with both acquired and inherited causes, each presenting clinically with hypocalcaemia.

- Familial isolated hypoparathyroidism is characterised by hypocalcaemia and hyperphosphataemia and may be due to an inherited deficiency or the abnormal activity of parathyroid hormone.

- Recently, a homozygous deletion within the human GCM2 gene has been shown to underlie hypoparathyroidism in one patient, while other compelling evidence indicates a critical role for GCM2 in normal parathyroid gland function.

- Mutation studies revealed a novel homozygous missense mutation of the DNA binding domain of GCM2, functional analysis of which now provides an important tool for the further delineation of GCM2 bioactivity and molecular mechanisms necessary for parathyroid gland development.

consequent hypoparathyroidism. ${ }^{17}$ Taken together, these studies provide compelling evidence for a critical role of GCM2 in normal parathyroid gland function; however the molecular basis and interactions required in this process remain unclear.

Here we report a consanguineous Pakistani family with multiple individuals presenting in early life with autosomal recessive FIH. Mutation studies revealed a novel homozygous missense mutation of the DNA binding domain of GCM2, functional analysis of which now provides an important tool for the further delineation of GCM2 bioactivity and molecular mechanisms necessary for parathyroid gland development.

\section{METHODS}

\section{Clinical data}

Subject IV:2 (fig 1), the second child of first cousin parents, was diagnosed as a neonate with primary hypoparathyroidism after presenting with convulsions. Her older sister had died in infancy following seizures and retrospectively was assumed to be similarly affected. The proband had no evidence of immunodeficiency, renal abnormalities, autoimmune disease, or dysmorphism. Physical examination was unremarkable; in particular, she had no evidence of neuromuscular irritability. Renal, liver, and thyroid functions

Abbreviations: CASR, calcium sensing receptor; EMSA, electrophoretic mobility shift assays; FlH, familial isolated hypoparathyroidism; PTH, parathyroid hormone 
A

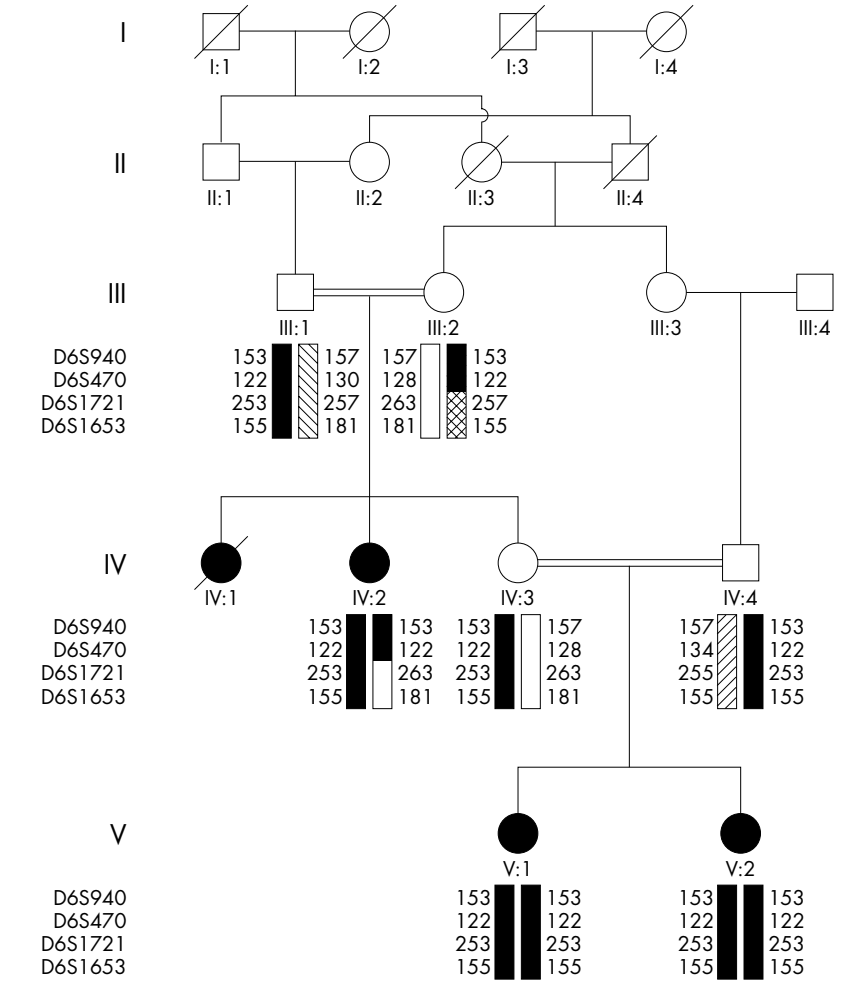

C

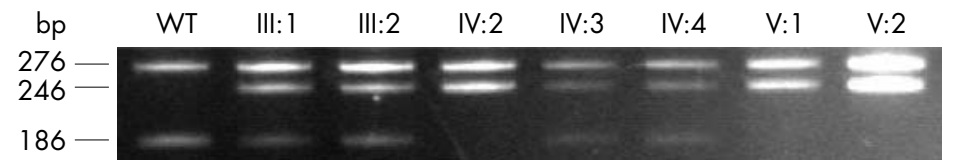

B

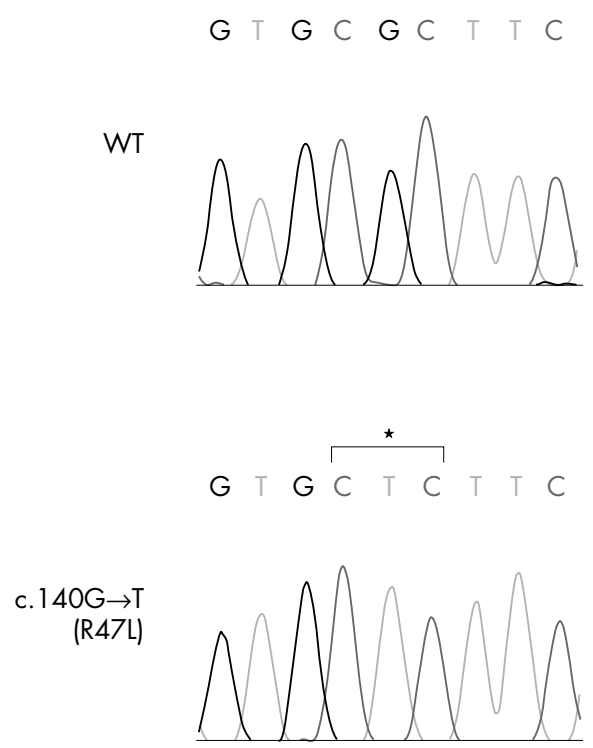

$G T G C \mathbf{N} C T T C$

Heterozygote

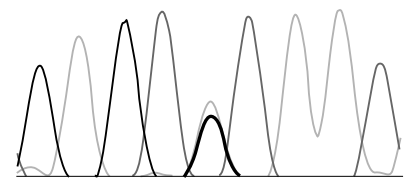

Figure 1 (A) Pedigree structure of the family with genotyping showing linkage to the GCM2 locus. Transmission of the phenotype is compatible with an autosomal recessive mode of inheritance. Genotype data are shown for the region encompassing markers D6S940 to D6S1653, spanning a 4.6 Mb interval. (B) Sequence chromatogram illustrating the GCM2 R47L mutation. Affected individuals carry a homozygous G $\rightarrow T$ substitution at nucleotide 140 (indicated by an asterisk). Nucleotides are numbered according to the cDNA sequence, with the adenosine of the initiation codon designated +1 . (C) Segregation of the mutation was tracked through the family by Hhal digestion of PCR products. Mutation carriers are detected by the presence of a 246 bp band due to loss of an Hhal site. Gel lanes correspond to the individuals numbered in the pedigree (lane 1, normal control).

were all normal. Biochemical investigations confirmed hypocalcaemia with a calcium level of $1.98 \mathrm{mmol} / \mathrm{l}$ (normal range 2.13-2.58), phosphate $2.02 \mathrm{mmol} / \mathrm{l}$ (normal range, 1.30-2.20), and a low PTH level of $5 \mathrm{ng} / \mathrm{l}$ (normal range, 12-72), findings compatible with primary hypoparathyroidism. She was treated with alphacalcidol and subsequent growth and development were reported to be normal.

The unaffected sister of subject IV:2 married a first cousin and subsequently had two children (V:1 and V:2), both diagnosed clinically with primary hypoparathyroidism. Individual V:1 was a full term normal delivery, weighing $3.2 \mathrm{~kg}$. She presented at 6 weeks of age with focal seizures involving the left arm and leg associated with left sided facial twitching. Laboratory investigation revealed hypocalcaemia at $1.35 \mathrm{mmol} / \mathrm{l}$ and hyperphosphataemia at $3.23 \mathrm{mmol} / \mathrm{l}$. Alkaline phosphatase was markedly elevated at $1805 \mathrm{U} / \mathrm{l}$ (normal range, 76-196). Serum calcium levels were maintained by calcium and vitamin $\mathrm{D}$ supplementation. At presentation, magnesium was $0.69 \mathrm{mmol} / \mathrm{l}$ (normal range, 0.70-1.00), PTH level was less than $10 \mathrm{ng} / \mathrm{l}$, and 25-hydroxy vitamin D level measured $11 \mathrm{nmol} / \mathrm{l}$ (normal range, 15.0100.0). Chromosome analysis showed a normal female karyotype and FISH studies for the DiGeorge/velo-cardiofacial syndrome region on chromosome 22 showed no deletion.
Her younger sister (subject V:2) was a full term normal delivery weighing $2.75 \mathrm{~kg}$. Because of the family history, she was screened for hypocalcaemia shortly after birth and initial serum calcium was $1.97 \mathrm{mmol} / \mathrm{l}$. PTH level was at the lower end of the normal range $(10 \mathrm{ng} / \mathrm{l})$. She was also treated with vitamin D and calcium supplementation.

Informed consent was obtained from all subjects or their parents and the study was approved by the relevant local research ethics committees.

\section{Molecular genetic analysis}

Genomic DNA was extracted from $10 \mathrm{ml}$ of peripheral blood by standard techniques. Autozygosity mapping was performed using fluorescently labelled microsatellite markers with an average heterozygosity of $75 \%$. Markers for each locus are listed in table 1. PCR amplifications were achieved using MJ Research (Waltham, MA) DNA Engines (10 $\mu \mathrm{l}$ reactions; $50 \mathrm{ng}$ DNA, $1.5 \mathrm{mM} \mathrm{MgCl}_{2}, 0.2 \mathrm{mM}$ dNTPs (Pharmacia, St Albans, Hertfordshire), $0.3 \mu \mathrm{M}$ primer, 0.5 $\mathrm{U}$ Taq polymerase (ABgene, Epsom, UK) in a $10 \times \mathrm{KCl}$ PCR buffer). PCR products were electrophoresed through 6\% polyacrylamide gels (FMC Bioproducts, Rockland, ME) on an ABI 377 DNA sequencer (Applied Biosystems, Foster City, CA) and analysed using GeneScan v3.0 and Genotyper v2.1 software (PE-ABI, Foster City, CA). Linkage to candidate loci 
was examined under the assumption that FIH was segregating as an autosomal recessive trait due to homozygous mutation inherited common by descent.

\section{Mutation analysis of GCM2}

The complete protein coding region and intron/exon boundaries of the GCM2 gene were amplified from all available family members and one normal control individual by PCR in $40 \mu \mathrm{l}$ reactions. Primer sequences for PCR products spanning the five coding exons are listed in table 2 . PCR products were separated by electrophoresis through $2 \%$ LE agarose (Cambrex, East Rutherford, NJ) to ensure the presence of sufficient quantities for sequence analysis, and were purified using the QIAquick PCR purification kit (Qiagen, Valencia, CA). Purified PCR products were sequenced, using the same forward primers as for the PCR reactions, with the Applied Biosystems BigDye terminator kit on an ABI 377 sequencer.

The mutation identified in family 1 , at nucleotide position 140 in exon 2, abolished an HhaI restriction endonuclease recognition site. We therefore independently confirmed segregation of the variant within the family by restriction analysis with HhaI (New England Biolabs, Beverly, MA), and tested a panel of chromosomes from demographically matched control individuals. An 1198 bp fragment containing exons 2 and 3 was amplified by PCR under identical conditions as those described above, using primers GCM2ex2F and GCM2ex3R. Each PCR product was digested with $10 \mathrm{U}$ enzyme at $37^{\circ} \mathrm{C}$ for $90 \mathrm{~min}$. After digestion, the DNA fragments were separated on a 3\% LE agarose gel and visualised with ethidium bromide.

\section{Preparation of GCM constructs}

Full length human GCM2 cDNA in pBluescript was kindly donated by A Giangrande. ${ }^{14}$ Using this plasmid as template, the arginine to leucine (R47L) point mutation was introduced by QuickChange (Stratagene, La Jolla, CA) site directed mutagenesis, according to the manufacturer's protocol. The entire GCM2 and R47L coding sequences were amplified by PCR using primers GCM2-5'BamHI and GCM2-3'XhoI (primer sequences available on request). Products were digested with BamHI and XhoI and inserted into the same sites of the eukaryotic expression vector pCMV-Tag3B (Stratagene) to facilitate the incorporation of a 5' c-Myc epitope. All constructs were verified by automated DNA sequencing.

\section{Transfection and immunoblotting}

COS cells were maintained at $37^{\circ} \mathrm{C}$ and $5 \% \mathrm{CO}_{2}$ in Dulbecco's modified Eagle's medium (DMEM) supplemented with 10\% fetal calf serum and antibiotics. Cells were seeded onto $10 \mathrm{~cm}$ dishes and transiently transfected with $8 \mu \mathrm{g}$ of expression plasmid using FuGene 6 reagent (Roche Molecular Biochemicals, Indianapolis, IN) according to the manufacturer's

\begin{tabular}{llll}
$\begin{array}{l}\text { Table } 1 \\
\text { loci }\end{array}$ & \multicolumn{3}{l}{ Microsatellite markers spanning the known FIH } \\
\hline Locus & Markers & Distance $(M b)$ & Heterozygosity \\
\hline PTH & D11S1315 & 12.7 & 0.54 \\
& D11S569 & 13.1 & 0.84 \\
& D11S1794 & 13.3 & 0.84 \\
& D11S861 & 14.4 & 0.70 \\
GCM2 & D11S1981 & 17.0 & 0.83 \\
& D6S940 & 9.9 & 0.66 \\
& D6S470 & 10.1 & 0.80 \\
& D6S1721 & 12.8 & 0.77 \\
& D6S1653 & 14.5 & 0.75 \\
\hline
\end{tabular}

recommendation. COS cells were harvested after $48 \mathrm{~h}$ and total cell extracts were prepared as described. ${ }^{18}$ Protein concentrations were quantified using the Bio-Rad (Hercules, CA) protein assay. Samples were separated by SDS-PAGE ( $10 \%$ acrylamide), transferred to nitrocellulose membrane, and stained with Ponceau $S$ to visualise protein bands. After immunoblot analysis, the membrane was washed with PBS-Tween wash buffer $\left(80 \mathrm{mM} \mathrm{Na} \mathrm{HPO}_{4}, 20 \mathrm{mM}\right.$ $\mathrm{KH}_{2} \mathrm{PO}_{4}, 100 \mathrm{mM} \mathrm{NaCl}, 0.1 \%$ Tween-20), supplemented with 5\% non-fat dry milk (Marvel) for both the blocking solution and antibody diluent. Primary c-Myc antibody (Zymed, San Francisco, CA) was used at a 1:500 dilution. Horseradish peroxidase conjugated secondary antibody ( 1:2000 dilution; Sigma, St Louis, MO) was used to visualise bound primary antibody with ECL Plus Western Blotting Detection Reagent (Amersham Biosciences, Little Chalfont, UK).

\section{Electrophoretic mobility shift assays}

Sequences of DNA probes containing consensus (wt) and mutant (m3) GCM recognition sites were as described in Schreiber et al ${ }^{18}$ Double stranded probes were generated by annealing of complementary oligonucleotides and labelled with $\gamma$-dATP ${ }^{32} \mathrm{P}$ using $\mathrm{T} 4$ polynucleotide kinase (New England Biolabs).

Electrophoretic mobility shift assays (EMSA) were performed as described ${ }^{18}$ using $3 \mu \mathrm{g}$ whole cell extracts from transiently transfected COS cells. Protein samples were incubated with $0.5 \mathrm{ng}$ of ${ }^{32} \mathrm{P}$-labelled double stranded probe for $30 \mathrm{~min}$ at room temperature. Samples were loaded onto native $4 \%$ polyacrylamide gels (Flowgen, Nottingham, UK) and electrophoresed in $0.5 \times \mathrm{TBE}(45 \mathrm{mM}$ Tris, $45 \mathrm{mM}$ boric acid, $1 \mathrm{mM}$ EDTA, pH 8.3) at $180 \mathrm{~V}, 4^{\circ} \mathrm{C}$ for $75 \mathrm{~min}$. Competition assays were performed using unlabelled double stranded wildtype and competitor (m3) probes in 1-, 10-, 20-, and 50-fold molar excess.

\section{RESULTS}

\section{Autozygosity mapping}

All available family members were typed with polymorphic microsatellite markers spanning the PTH locus over a $4.3 \mathrm{Mb}$ interval. There was no evidence of linkage to $P T H$, with affected individuals displaying heterozygous genotypes for all markers across this region (data not shown).

Individuals were also typed for polymorphic markers flanking the GCM2 gene. The finding of homozygosity in affected individuals for all or some of these markers was considered compatible with linkage to GCM2 (fig 1A).

\section{Mutation analysis of GCM2}

We next sequenced all five coding exons and intron/exon boundaries of GCM2 for all available family members and identified a homozygous $\mathrm{G}$ to $\mathrm{T}$ transition at nucleotide position 140 (c.140G $\rightarrow \mathrm{T}$ ) in exon 2 , present in all affected individuals. This substitution results in a change in the amino acid at codon 47, within the DNA binding domain of GCM2, from the normal arginine to leucine. All unaffected parents were heterozygous for this R47L missense mutation.

The $\mathrm{G}$ to $\mathrm{T}$ transition eliminates an HhaI restriction site, hence we independently confirmed segregation of the mutation within the family by restriction analysis. An $1198 \mathrm{bp}$ fragment containing exons 2 and 3 was digested with HhaI. Normal individuals (homozygous wildtype) produce five fragments of size 352, 324, 276, 186, and $60 \mathrm{bp}$. Affected individuals IV:2, V:1, and V:2, homozygous for the R47L mutation, lose the cut site at nucleotide position 140 and produce a $246 \mathrm{bp}$ fragment in place of the 186 and $60 \mathrm{bp}$ fragments. Heterozygous parents of affected individuals, carrying one normal and one mutant allele, display all 
Table 2 Primer sequences for GCM2 gene amplification

\begin{tabular}{|c|c|c|c|}
\hline Exon & Primer name & Primer sequence $\left(5^{\prime} \rightarrow 3^{\prime}\right)$ & Amplicon size (bp) \\
\hline 1 & $\begin{array}{l}\text { GCM2exiF } \\
\text { GCM2exlR }\end{array}$ & $\begin{array}{l}\text { TAACCATTGTCCCCAGCTTC } \\
\text { TCCGCAGACTCTTCAAGAAC }\end{array}$ & 361 \\
\hline \multirow{2}{*}{2} & & & \\
\hline & $\begin{array}{l}\text { GCM2ex2F } \\
\text { GCM2ex2R }\end{array}$ & $\begin{array}{l}\text { TGGCAIIIGGCCTITGACG } \\
\text { CCAGCCTGAGTGACAGAGTG }\end{array}$ & 498 \\
\hline \multirow[t]{2}{*}{3} & GCM2ex3F & GAGTTCTTGGTCCCAGCTAATT & 315 \\
\hline & GCM2ex3R & CCACTGGGGCTGTATTTIGT & \\
\hline \multirow{2}{*}{4} & GCM2ex4F & GAGCCTGTTTATTTGTCAAGA & 410 \\
\hline & GCM2ex4R & TCAGATGAAATCAAACCCTTG & \\
\hline \multirow[t]{4}{*}{5} & GCM2ex5aF & CACAACACAGAGCCCAGCAC & 593 \\
\hline & GCM2ex5aR & AAGAGATCATTGCCATTTCACA & \\
\hline & GCM2ex5bF & ATGACACAGACTGGGTTCATC & 699 \\
\hline & GCM2ex5bR & CCTGAAACTGCCCATGGTT & \\
\hline
\end{tabular}

six fragments. Figure $1 \mathrm{~B}$ and $\mathrm{C}$ illustrates the R47L mutation identified and segregation of this mutation within the family. A cohort of 108 chromosomes from healthy unrelated Pakistani control subjects was screened for the presence of the mutation. All controls demonstrated a wildtype genotype, implying that the DNA variant is highly unlikely to represent a sequence polymorphism.

\section{Effect of R47L mutation on DNA binding ability of GCM2}

To assess whether the R47L amino acid substitution altered the DNA binding ability of the mutant GCM2 protein, we performed EMSA. Significant levels of expression of both wildtype and mutant GCM proteins following transfection were determined by means of western blotting. Normal levels of both proteins were detected in cell extracts subsequently used for EMSA experiments (fig 2C).

Using a ${ }^{32} \mathrm{P}$-labelled oligonucleotide containing the known DNA binding recognition site for GCM proteins, EMSA reactions were performed with extracts from COS cells transfected with full length wildtype GCM2 cDNA or full length GCM2 containing the R47L substitution. Cells transfected with empty vector (pCMV-Tag3B) were used as a negative control. Binding of GCM2 to the recognition site was readily detected for wildtype protein and was competed out with increasing amounts of unlabelled self-competitor probe, indicating the binding to be specific. Protein containing the R47L mutation was unable to bind to the GCM binding site, implying that substitution of leucine for arginine at this residue abolishes normal DNA binding ability of the GCM2 protein (fig 2D).

\section{DISCUSSION}

FIH is known to be a heterogeneous disorder with mutations in the PTH gene, encoding parathyroid hormone, being described in both autosomal dominant and autosomal recessive cases..$^{3-5}$ PTH secretion is normally regulated by the G protein-coupled CASR, functioning as a negative feedback loop; heterozygous defects in the CASR gene resulting in constitutive receptor activation have also been detected in autosomal dominant FIH. ${ }^{7}{ }^{9}$ In addition to these two genes described, there has been a single report of a mutation in the Drosophila glial cells missing $(\mathrm{gcm})$ human homologue, GCM2, encoding a transcription factor implicated in parathyroid gland development.

In a highly consanguineous Pakistani family within which autosomal recessive FIH is segregating, we report a novel missense mutation of the GCM2 gene. This is only the second report of a mutation of the GCM2 gene, and the first to identify a critical domain of the GCM2 protein necessary for control of parathyroid tissue development. We used autozygosity mapping, initially to exclude linkage to a known gene causative of autosomal recessive FIH, namely the PTH locus. We next identified a region of homozygosity extending over an interval of $180 \mathrm{~kb}$, proximal to the GCM2 gene (fig 1A). Direct sequence analysis of all coding GCM2 exons showed all three affected individuals to be homozygous for an Arg47Leu amino acid substitution, the first missense mutation to be reported in this gene which encodes a transcription factor. Unaffected parents were heterozygous for the mutation, which co-segregated with the disease phenotype and was absent from normal controls, producing compelling evidence that this missense mutation represents the inherited basis of hypoparathyoidism in this kindred (fig $1 \mathrm{~B}$ and $\mathrm{C}$ ). The only previously reported mutation of the GCM2 gene in FIH is a large homozygous deletion of exons $1-4 .^{11}$ The present study demonstrates that a missense mutation within the conserved DNA binding domain of GCM2 is sufficient to cause an FIH phenotype.

The substituted arginine residue is conserved amongst its mouse and Drosophila homologues, indicating a potentially important and functional role in GCM2 activity (fig 2A). Arginine residues are positively charged, polar amino acids, which play a significant role in structure. They are frequently involved in salt bridges, where they pair with negatively charged amino acids to form stable hydrogen bonds, important for protein stability. ${ }^{19}$ The replacement of arginine with the similarly positively charged lysine in the GCMI isoforms provides further evidence of an important role for this amino acid residue within the GCM DNA binding domain. The affected individuals in our FIH kindred have a homozygous substitution of leucine for arginine at position 47. The amino acid leucine, in contrast to arginine residues, is aliphatic and hydrophobic, preferring to be situated within protein hydrophobic cores. In addition, this highly nonreactive amino acid favours a position within alpha helices, rather than in $\beta$ strands. ${ }^{19}$ Recently, Cohen et a ${ }^{20}$ solved the crystal structure of the GCM domain-DNA complex, defining the amino acid residues that make contact with the DNA. The GCM domain exists as two $\beta$ sheet domains, which form a clamp, seizing the DNA from two sides of the major groove. The upper jaw of the clamp is formed by the $\beta$ sheet of the larger domain, with its strands orientated orthogonally to the DNA axis. Analysis of the predicted protein structure of GCM2 indicates that the arginine residue substituted in this hypoparathyroidism family is not involved directly in DNA binding (fig 2B). However, EMSA analysis has demonstrated abrogation of DNA binding activity when the arginine to leucine mutation is introduced at amino acid position 47 (fig $2 \mathrm{D}$ ). This residue lies in the large $\beta$ sheet domain, but is located on the outer surface of the protein, and does not contact the DNA substrate. Taken together, these data 
A

GCM2 1 MPAAAVQEAV GVCSYGMQLS WDINDPQMPQ EL.ALFDQFR EWPDGYVRFT

mGcm2 MPADSTQDED AVLSYGMKLT WDINDPQMPQ EP.THFDHFR EWPDGYVRFI

GCMI ....MEPDD SDSEDKEILS WDINDVKLPQ NV. KKTDWFQ EWPDSYAKHI

mGcml …MELDD FDPEDKEILS WDINDVKLPQ NV.KTTDWFQ EWPDSYVKHI

rGcm l ....MELDD FDPEDKEILS WDINDMKLPQ NV.KKTDWFQ EWPDSYVKHI

dGCM2 QQAGGSMTMP SSSTGKGKRE WDINDAIVPH VPDQEFDEFN EWSDGHVRHI

dGCM MPVPMPVPSP PATKSRVAID WDINDSKMPS VG..EFDDFN DWSNGHCRLI

GCM2 50 YSSDEKKAQR HLSGWAMRNT NNHNGHILKK SCLGVVVCTO ACTLPDGSRL mGcm2 YSSQEKKAQR HLSGWAMRNT NNHNGHILKK SCLGVVVCAR ACALKDGSHL

GCM1 YSSEDKNAQR HLSSWAMRNT NNHNSRILKK SCLGVVVCGR DCLAEEGRKI

$\mathrm{mGcm} 1$ YSSDDRNAQR HLSSWAMRNT NNHNSRILKK SCLGVVVCSR DCSTEEGRKI

rGcm 1 YSSDDRSAQR HLSSWAMRNT NNHNSRILKK SCLGVVVCSR DCSTEEGRKI

dGCM2 YSLHNEEAKK HISGWAMRNT NNHNVNILKK SCLGVLVCSQ HCTLPNGSKI

dGCM YSVQSDEARK HASGWAMRNT NNHNVNILKK SCLGVLLCSA KCKLPNGASV

B

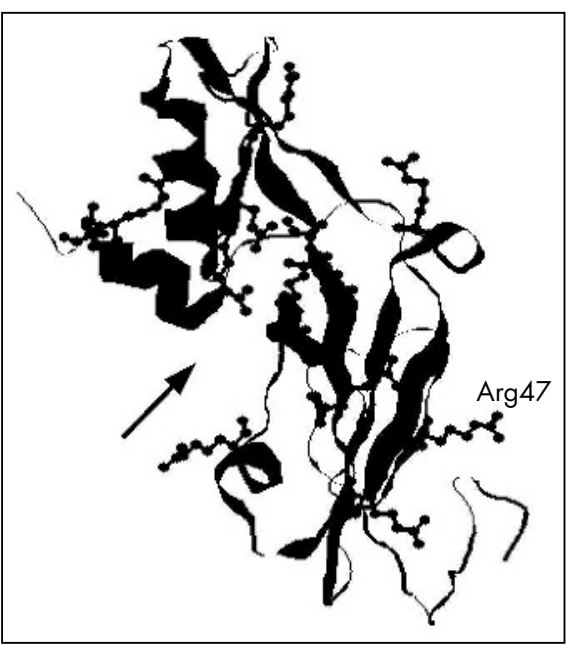

C

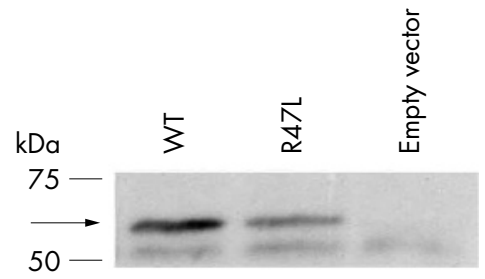

Figure 2 (A) Sequence alignment of human (GCM1, GCM2), mouse ( $\mathrm{mGcm} \mathrm{1,} \mathrm{mGcm} 2)$, rat ( $\mathrm{rGcm} 1)$, and fly (dGCM, dGCM2) proteins in the DNA binding domain. Conserved amino acids are boxed; numbers indicate amino acid positions of human GCM2 protein. The arrow identifies the position of the R47L substitution. (B) Predicted structure of normal GCM2 protein backbone, with arginine residues highlighted in ball-and-stick format. The arrow identifies the predicted DNA binding region. Position of the native arginine residue at position 47, substituted for leucine in affected individuals, is indicated. (C) Western blot demonstrating expression of wildtype and mutant GCM2, indicated by the horizontal arrow. Size ladder is shown in kDa. (D) Electrophoretic mobility shift assay showing binding ability of normal and mutant proteins to radio labelled probe containing the GCM DNA binding site. Contents of lanes are indicated above the gel image. Competition assays were performed with 1-, 10-, 20-, and 50-fold molar excess of self and non-self competitors. The R47L mutation abolishes DNA binding ability of the GCM2 protein. Figure indicates DNA-protein complexes (C) and free probes $(\mathrm{F})$. 
suggest DNA binding activity of GCM2 may be dependent on complex formation with one or more additional proteins, and we hypothesise that disruption of this protein-protein interaction represents the molecular mechanism leading to FIH in this family.

Although the function of human GCM2 remains unknown, studies using mouse Gcm2 and Drosophila GCM2 provide some insight into the expression patterns and transcriptional activity of this protein. In Drosophila, GCM proteins are transiently expressed in glial precursors and act as a binary switch between neuronal and glial cell determination. ${ }^{12}$ From sequence homology, indicating a potential conservation of function, mammalian GCM proteins may be expected to be involved in gliogenesis. ${ }^{22}$ However, expression studies have shown murine $\mathrm{Gcml}$ and $\mathrm{Gcm} 2$ to be expressed in trophoblast cells during placental development and in developing parathyroid glands, respectively. ${ }^{16}{ }^{23}$ Despite containing two separate transactivation domains, $\mathrm{Gcm} 2$ is a poor transcriptional activator when compared to $\mathrm{Gcml}$, and is unable to initiate the neuron-glia transformation when expressed as a transgene in the developing nervous system of Drosophila. ${ }^{16}{ }^{22} 24$ Targeted deletion of the mouse Gcm2 gene results in absence of parathyroid glands and undetectable PTH expression in the thyroid and neck of homozygous mice. ${ }^{17}$ These mice develop hypoparathyroidism but with normal serum PTH levels, insufficient to correct the hypocalcaemia. This compensatory PTH is synthesised in the thymus, where PTH positive cells are shown to express Gcml and Casr. ${ }^{17}$ Of interest, affected members in the family we investigated each had detectable but sub-normal levels of circulating PTH.

In summary, the present study reinforces the critical role of GCM2 activity in human parathyroid gland development through molecular analysis of an autosomal recessive FIH family. Detailed characterisation of GCM2 mutations associated with FIH is warranted and will likely provide insight into the molecular pathways necessary for PTH secreting cells. These findings have more immediate relevance for the diagnosis and management of families presenting with isolated hypoparathyroidism.

\section{ACKNOWLEDGEMENTS}

We thank the family members for their participation.

\footnotetext{
Authors' affiliations

L Baumber, C Tufarelli, R C Trembath, Division of Medical Genetics, Departments of Genetics and Cardiovascular Sciences, University of Leicester, Leicester, UK

S Patel, Leicestershire Genetics Centre, University Hospitals of Leicester NHS Trust, Leicester, UK

P King, Derby Royal Infirmary, Derby, UK

C A Johnson, E R Maher, Section of Medical and Molecular Genetics, Department of Paediatrics and Child Health, University of Birmingham Medical School, Birmingham, UK

This work was supported by a Wellcome Trust grant (programme grant 062346/Z/00/Z, Functional Genomics National Autozygosity Mapping Resource). CT is a Royal Society Dorothy Hodgkin Research Fellow.

Competing interests: none declared

Ethics approval: approval was obtained from the Leicestershire research ethics committee.

Correspondence to: Richard C Trembath, Professor of Medical Genetics, Division of Medical Genetics, Departments of Genetics and Cardiovascular Sciences, University of Leicester, University Road, Leicester LE1 7RH, UK; rtrembat@hgmp.mrc.ac.uk
}

Received 3 September 2004

Revised version received 26 October 2004

\section{REFERENCES}

1 Garfield N, Karaplis AC. Genetics and animal models of hypoparathyroidism. Trends Endocrinol Metab 2001;12:288-94.

2 Ahn TG Antonarakis SE, Kronenberg HM, Igarashi T, Levine MA. Familial isolated hypoparathyroidism: a molecular genetic analysis of 8 families with 23 affected persons. Medicine 1986;65:73-81

3 Arnold A, Horst SA, Gardella TJ, Baba H, Levine MA, Kronenberg HM. Mutation of the signal peptide-encoding region of the preproparathyroid hormone gene in familial isolated hypoparathyroidism. J Clin Invest 1990;86:1084-7

4 Parkinson DB, Thakker RV. A donor splice site mutation in the parathyroid hormone gene is associated with autosomal recessive hypoparathyroidism. Nat Genet 1992;1:149-52.

5 Sunthornthepvarakul T, Churesigaew S, Ngowngarmratana S. A novel mutation of the signal peptide of the preproparathyroid hormone gene associated with autosomal recessive familial isolated hypoparathyroidism. J Clin Endocrinol Metab 1999;84:3792-6.

6 Brown EM, Gamba G, Riccardi D, Lombardi M, Butters R, Kifor O, Sun A, Hediger MA, Lytton J, Hebert SC. Cloning and characterization of an extracellular $\mathrm{Ca}^{2+}$-sensing receptor from bovine parathyroid. Nature 1993;366:575-80

7 Baron J, Winer KK, Yanovski JA, Cunningham AW, Laue L, Zimmerman D Cutler GB Jr. Mutations in the $\mathrm{Ca}^{2+}$-sensing receptor gene cause autosomal dominant and sporadic hypoparathyroidism. Hum Mol Genet 1996;5:601-6

8 De Luca F, Ray K, Mancilla EE, Fan G-F, Winer KK, Gore P, Spiegel AM, Baron J. Sporadic hypoparathyroidism caused by de novo gain-of-function mutations of the $\mathrm{Ca}^{2+}$-sensing receptor. J Clin Endocrinol Metab 1997:82:2710-5.

9 Watanabe T, Bai M, Lane CR, Matsumoto S, Minamitani K, Minagawa M, Niimi H, Brown EM, Yasuda T. Familial hypoparathyroidism: identification of a novel gain of function mutation in transmembrane domain 5 of the calciumsensing receptor. J Clin Endocrinol Metab 1998;83:2497-502.

10 Nagase T, Murakami T, Tsukada T, Kitamura R, Chikatsu N, Takeo H, Takata N, Yasuda H, Fukumoto S, Tanaka Y, Nagata N, Yamaguchi K, Akatsu T, Yamamoto M. A family of autosomal dominant hypocalcemia with a positive correlation between serum calicum and magnesium: identification of a novel gain of function mutation ( $\mathrm{Ser}^{820} \mathrm{Phe}$ ) in the calcium-sensing receptor. $J$ Clin Endocrinol Metab 2002;87:2681-7.

11 Ding C, Buckingham B, Levine MA. Familial isolated hypoparathyroidism caused by a mutation in the gene for the transcription factor GCMB. J Clin Invest $2001 ; 108: 1215-20$

12 Akiyama Y, Hosoya T, Poole AM, Hotta Y. The gem-motif: a novel DNAbinding motif conserved in Drosophila and mammals. Proc Natl Acad Sci US A 1996;93:14912-6.

13 Altshuller Y, Copeland NG, Gilbert DJ, Jenkins NA, Frohman MA. Gcm 1, a mammalian homolog of Drosophila Glial Cells Missing. FEBS Lett 1996;393:201-4.

14 Kammerer M, Pirola B, Giglio S, Giangrande A. GCMB, a second human homolog of the fly glide/gcm gene. Cytogenet Cell Genet 1999;84:43-7.

15 Kanemura Y, Hiraga S, Arita N, Ohnishi T, Izumoto S, Mori K, Matsumura H, Yamasaki M, Fushiki S, Yoshimine T. Isolation and expression analysis of a novel human homologue of the Drosophila glial cells missing $(\mathrm{gcm})$ gene. FEBS Lett 1999;442:151-6.

16 Kim J, Jones BW, Zock C, Chen Z, Wang H, Goodman CS, Anderson DJ. Isolation and characterization of mammalian homologs of the Drosophila gene glial cells missing. Proc Natl Acad Sci U S A 1998;95:12364-9.

17 Gunther T, Chen ZF, Kim J, Priemel M, Rueger JM, Amling M, Moseley JM, Martin TJ, Anderson DJ, Karsenty G. Genetic ablation of parathyroid glands reveals another source of parathyroid hormone. Nature 2000;406:199-203

18 Schreiber J, Enderich J, Wegner M. Structural requirements for DNA binding of GCM proteins. Nucleic Acids Res 1998;26:2337-43.

19 Betts MJ, Russell RB. Amino acid properties and consequences of substitutions. In: Barnes MR, Gray IC, eds. Bioinformatics for geneticists. London: Wiley, 2003.

20 Cohen SX, Moulin M, Hashemolhosseini S, Kilian K, Wegner M, Muller CW Structure of the GCM domain-DNA complex: a DNA-binding domain with a novel fold and mode of target site recognition. EMBO J 2003;22:1835-45

21 Kammerer M, Giangrande A. Glide2, a second glial promoting factor in Drosophila melanogaster. EMBO J 2001;20:4664-73.

22 Tuerk EE, Schreiber J, Wegner M. Protein stability and domain topology determine the transcriptional activity of the mammalian glial cells missing homolog, GCMb. J Biol Chem 2000;275:4774-82.

23 Schreiber J, Riethmacher-Sonnenberg E, Riethmacher D, Tuerk EE, Enderich J, Bosl MR, Wegner M. Placental failure in mice lacking the mammalian homolog of glial cells missing, GCMa. Mol Cell Biol 2000;20:2466-74.

24 Wegner M, Riethmacher D. Chronicles of a switch hunt: gcm genes in development. Trends Genet 2001;17:286-90. 